\title{
LAS POLÍTICAS DE SEGURIDAD Y DEFENSA EN PARAGUAY: PERSPECTIVAS Y DESAFIOS FRENTE AL NUEVO ESCENARIO POLÍTICO
}

Sonia Winer*

Universidad de Buenos Aires

Resumen: El artículo se produce a partir de las siguientes preguntas: ¿Cuáles son las razones por las que las clases dominantes guaraníes adoptaron la ideología securitaria estadounidense como propia, en especial entre 2001 y 2003? ¿Este hecho resultaría de la necesidad de salir de una crisis coyuntural al inicio del periodo y que conducirían a las elites de ésta nación hacia una alianza con la administración republicana? ¿Que intereses motivan a la potencia hegemónica a intervenir en este pequeño país sudamericano bautizado por el escritor Roa Bastos como "el agujero negro de América Latina"? ¿Y cuáles son los desafíos y condicionamientos que deberá enfrentar el presidente Fernando Lugo (y la Alianza Patriótica para el Cambio-APC) en materia de políticas públicas? ¿Qué estrategias podrían fortalecer las posiciones de los movimientos sociales y partidos políticos de izquierda que integran dicha alianza para forzar políticas anti-hegemónicas en materia de administración del conflicto social?

Palabras clave: Seguridad y Defensa; Paraguay; USA; siglo XXI

\section{The safety and defense politics in Paraguay: perspectives and chal- lenges before the new politic setting}

\begin{abstract}
: the article was created from the following questions: which are the reasons for the indian guaranies dominant classes adopt the north-american security ideology as their own, especially between 2001 and 2003? Would it result from the need of leaving a crisis referring to the conjuncture of the beginning of the analyzed period and would that lead the elites of this nation to an alliance with the republican administration? Which interests motivates the hegemonic potency to interfere in this small South American country baptized by the writer Roa Bastos as "the Latin American black hole"? And which are the challenges and conditionings that the president Fernando Lugo (and the Patriotic Alliance for Change APC) must face in public politics? Which "left" politician that integrates such alliance to force anti-hegemonic politics in matter of social conflict administration?
\end{abstract}

* Becaria del CONICET. 
Key Words: Security and Defense; Paraguay; USA; $21^{\text {st }}$ century.

\section{Introducción}

En esta publicación apenas podrán esbozarse algunas líneas de trabajo, planteadas a partir del estudio de caso centrado en torno a la experiencia del denominado Congreso Democrático del Pueblo - CDP. La misma se investiga bajo el marco teórico que entiende a las políticas públicas paraguayas de Seguridad como una arena dinámica de conflicto que expresa el estado de la correlación de fuerzas entre clases antagónicas ${ }^{1}$. Definición que, a su vez, conduce a interpretarlas como 'respuestas' complejas del aparato represivo estatal a la movilización de las clases subalternas ${ }^{2}$. Por lo tanto, en la siguiente publicación, se busca explicar por qué dichas 'soluciones' implementadas desde el 2001 en Paraguay, apuntaron a profundizar el castigo sobre los movimientos sociales ${ }^{3}$ y sobre las principales organizaciones campesinas guaraníes: la Mesa Coordinadora Nacional de Organizaciones Campesinas -MCNOC (que aglutina a mas de veinticinco organizaciones zonales, regionales y nacionales); la Comisión Nacional de Lucha por la Reforma Agraria, cuyos referentes mas importantes son la Federación Nacional Campesina - FNC; y la Federación Nacional Campesina - ONAC. En el periodo analizado la dirigencia rural había acumulado experiencias de lucha en un país que concentra grandes sectores de su población en el campo, liderazgo que actuó como elemento dinámico y aglutinador de demandas al interior de los diversos movimientos (como los movimientos juveniles y de mujeres que emergieron con fuerza en la escena pública a principio del nuevo milenio), así como de las debilitadas y divididas seis centrales sindicales ${ }^{4}$ paraguayas y de diversos actores que se reunieron en el CDP. Autores como Fogel ${ }^{5}$ y Riquelme ${ }^{6}$ coinciden sobre los altos niveles de consciencia de estos sectores, así como en su capacidad para articular colectivamente la resistencia cuando se afectan sus intereses particulares, y también -en determinados momentos históricos como el analizado- los de la sociedad en general. Claro ejemplo de ello fue la inclusión de demandas de la ciudadanía en el CDP como la lucha contra la corrupción y la impunidad, y en particular la oposición a la ley antiterrorista promovida por Estados Unidos. Esto les valió la categorización de ‘sujetos amenazantes' por parte de las clases dominantes nacionales y trasnacionales?

Nuestra hipótesis sostiene que la exitosa experiencia organizativa del CDP forzó una 'reacción' represiva que, sustentada en un clima de temor internacional post 11 de septiembre, consiguió institucionalizar la intervención militarizada, la cual pretende entonces aceitar los mecanismos de control social tanto rurales como urbanos, boicoteando cualquier intento de integración regional sudamericano contrario a las propuestas de 
Las políticas de Seguridad y Defensa en Paraguay: perspectivas y desafíos frente al nuevo escenario político

la potencia hegemónica estadounidense y de los sectores tradicionales de poder guaraníes.

\section{La crisis de 2001 y la organización del CDP: su constitución como "sujeto amenazante"}

Durante el 2001 la economía paraguaya registró un estancamiento y una inflación oficial del $8,4 \%$, junto con una brutal pérdida de la capacidad de consumo de la población y la devaluación del salario de trabajadores y trabajadoras del campo y la ciudad ${ }^{8}$. Las cifras de desempleo treparon por entonces al $37,4 \%$, mientras que en las ciudades los índices se incrementaban hasta el 40,7\%. La pobreza afectaba a más de 2 millones 300 mil personas, con situaciones extremas en las zonas rurales y en los cinturones citadinos. ${ }^{9}$ Sobre esta base material se sustentaría en los años siguientes una pérdida de legitimidad de las autoridades nacionales, la multiplicación de acusaciones de corrupción, con el agravante de un progresivo retorno a prácticas represivas por parte de las Fuerzas policiales y de Seguridad que recuerdan la peor época de la dictadura de Stroessner (1954-1989) y que en realidad no habían sido erradicadas durante un periodo de "transición" que nunca pudo lograr una democracia que respetara al menos las garantías ciudadanas mas elementales. Parte de este problema se evidenció en la escena pública ya desde marzo de 1999, cuando sorprendió a propios y extraños el cruento atentado que acabó con la vida de Luis Maria Argaña, entonces vicepresidente de la República. Este episodio desembocó en una crisis política que puso en peligro la propia continuidad de la democracia representativa paraguaya. El entonces Presidente de la Nación fue sospechado de tener algún tipo de vínculo con el crimen, mientras que el célebre General Lino Oviedo, era acusado de la autoría intelectual del hecho. La posibilidad de un golpe de Estado sonaba de boca en boca, en medio de violentas protestas callejeras, donde nueve personas murieron blanco de francotiradores. Mientras, el entonces titular del Ejecutivo, Raúl Cubas Grau, renunciaba a su puesto apenas cinco días después del magnicidio, en tanto que Oviedo pasaría por el exilio, la cárcel, para terminar siendo liberado por la justicia guaraní en 2007 (su partido, la Unión Nacional de Ciudadanos Éticos-UNACE- logró consolidarse finalmente como tercera fuerza en las elecciones presidenciales del 20 abril de 2008 obteniendo el casi $22 \%$ de los votos) en medio de rumores que lo acusan de haber pactado con el saliente presidente Nicanor Duarte Frutos para impedir que el ex-obispo Fernando Lugo llegara al poder. Luego de los sucesos de 1999, el diputado colorado Luis González Macchi, tras una decisión del Congreso, se hacía cargo de la primera magistratura. Más tarde, la Corte Suprema anunciaba que este debía terminar el período de cinco años de Cubas Grau.

La precaria legitimidad de origen del nuevo presidente, se reflejaba en que 
ni siquiera conseguía los apoyos necesarios para una buena administración en su propio partido, que sufría una profunda división interna. Ya se desarrollará la manera en que esta etapa resulta un momento importante para la organización de los movimientos rurales, quienes se enfrentan a la aparición de grupos parapoliciales que actúan al margen de la legalidad (varios de cuyos integrantes pertenecían y pertenecen a la propia fuerza pública y son contratados por sectores del empresariado sojero y ganadero). El país queda ubicado en una situación de peligro y frente a un sentimiento de retorno al pasado. En ese contexto, el movimiento campesino intenta operar con cautela multiplicando las medidas de protesta, pero también los reclamos de democratización de las estructuras de poder y -sobre todo- fortaleciendo su oposición contraria a medidas que consideraba empeorarían la situación del Paraguay.

Solamente durante el 2001 se realizarán 73 acciones de protesta, suma sin precedentes desde 1989, que expresaban claramente el aumento de la conflictividad social.

Los conflictos por la tenencia de la tierra, de igual modo, se incrementan entre 1999 y 2001 en comparación con años anteriores (contabilizándose 67 casos de ocupaciones de terrenos, de las cuales 56 sufren desalojos con diferentes niveles de violencia, y un total de 1.839 detenciones) ${ }^{10}$ La situación de tensión entre los movimientos sociales y las autoridades del Estado creció para principios de 2002: el 20 de marzo, la FNC, en el marco de su acostumbrada marcha anual a Asunción, reunía 5000 personas bajo la consigna de paralizar la reforma de la banca pública (por considerar que era un paso previo a la privatización y por presumirla orientada hacia los intereses del capital financiero especulativo promovido por el Banco Mundial y el Fondo Monetario Internacional), exigir la industrialización del algodón, y la reactivación de la economía en general. En ese momento el Poder Ejecutivo presidido por González Macchi accedió a retirar el proyecto de la Banca del Congreso guaraní para realizar una nueva revisión con la participación de las organizaciones campesinas, en tanto prometía analizar el resto de las demandas con el fin de acallar el descontento popular.

El 17 de abril, el MCNOC también organizaba su movilización anual en Asunción y en once diferentes departamentos, enarbolando las banderas contra la privatización de las empresas estatales (como la de teléfonos y aguas), contando con el apoyo de las otras organizaciones campesinas (como la FNC) y de nuevos actores como la $\mathrm{CAP}^{11}$, además de sectores bien diversos, puesto que la inminente privatización de las mismas no solo inquietaba a campesinos y sindicalistas, sino también a otros segmentos de la denominada sociedad civil (organizaciones no gubernamentales y partidos políticos) debido a la poca trasparencia en el proceso y por existir fuertes sospechas de un gran negociado. Con el fin de conformar 
un frente común de resistencia a esta ofensiva gubernamental nacía un Frente en Defensa de los Bienes Públicos y del Patrimonio Nacional, integrado por la FNC, la ONAC, y otras organizaciones sindicales y políticas, que temían se repitiera en Paraguay lo sucedido con la ley de reforma del Estado votada en 1991 por el Congreso argentino a instancias del presidente Carlos Menem (con resultados catastróficos para amplias porciones de la población, la cual terminó quedando presa de monopolios con tarifas altísimas en servicios esenciales debido -en partea los altos niveles de corrupción conque se había concretado la venta).

A su vez, el caso del secuestro, tortura, y posterior asesinato de dos militantes de la organización de izquierda Patria Libre fue interpretado como una profunda incapacidad del gobierno colorado de resolver ciertos problemas por la vía institucional, habilitando el retorno a prácticas vigentes durante la dictadura de Stroessner. Para repudiar el hecho se constituía la Plenaria Popular contra el Terrorismo de Estado (donde participaban el MCNOC, ONGs, sectores estudiantiles y gremiales). Desde allí se dará comienzo a una serie de protestas y presentaciones judiciales ante organismos nacionales e internacionales denunciando las violaciones a los derechos humanos, momento en que se expone en el Parlamento guaraní el proyecto de ley antiterrorista exigido por la administración republicana estadounidense, el cual es percibido por los movimientos como una habilitación legal para reprimirlos y criminalizar la protesta social. ${ }^{12}$

Tanto el proceso de privatización de las empresas estatales, como el peligro de revivir el terrorismo de Estado, convocaron a los dos frentes de reciente formación a debatir estrategias de acción conjuntas para enfrentar al gobierno en los temas señalados. De esta unión finalmente surgirá el CDP, el cual instala a los movimientos campesinos guaraníes como "sujetos amenazantes" anti-sistémicos para la mirada estadounidense (que los homologa al zapatismo), en tanto éstos son quienes consiguen unir diversos sectores populares tras una serie reivindicaciones y prácticas comunes. Ambas, producto de un proceso mas amplio y progresivo de maduración que había costado casi una década construir, y que al fin convergía tras un programa de unidad (cuando diferentes organizaciones campesinas toman la decisión de plantear propuestas que superen el esquema puramente asistencial para pasar a las de tipo estructural, reclamando al Estado proyectos de desarrollo nacional basados en una reactivación económica global y no solo para el sector rural $^{13}$ ). Las actividades se fundamentaban en la necesidad de transformar la materia prima (sobre todo agrícola, dada la abundancia de mano de obra y de energía eléctrica), y a partir de una modificación en la percepción campesina que se planteaba que la salida de la crisis de producción del campo no podría realizarse de manera aislada, pues sus problemas más profundos se relacionaban con la manera en extremo particular cómo se dio históricamente la acumulación capitalista y de 
concentración de la tierra en Paraguay: "Nos dimos cuenta de que el problema agrario no se restringe solo al campo y al campesino, sino que es una cuestión nacional, ya que la crisis agraria está repercutiendo en los demás sectores, el de los comerciantes, de los profesionales, de los empleados". ${ }^{14}$

Aunque este proceso de pasar de la reivindicación a la proposición generó fisuras y diferencias en los gremios rurales (en especial en el año 1998 cuando se dividió el MCNOC), éstos lograron abrir un debate nacional sobre cual debía ser el modelo de desarrollo para el país guaraní (discusión en la que deciden no participar los partidos políticos tradicionales y que es mirada con suma preocupación por el Partido Colorado), que no surge de estrategas urbanos ni de sectores profesionales de la ciudad (aunque luego varios se suman), sino en el seno de los movimientos campesinos. Dentro de esta estrategia se plantea el impulso de diversos programas cuya ejecución debería estar dirigida por el Estado, pero bajo control y vigilancia del movimiento social, por lo tanto se precisaban realizar modificaciones institucionales hacia una democracia más participativa y menos delegativa. He aquí el carácter anti-sistémico de estas propuestas que venia dado, entonces, por el planteamiento de reformas estructurales en materia económica, de régimen político, y de política exterior.

Según Riquelme ${ }^{15}$, al concebirse la lucha por la tierra dentro de una estrategia general, se sentaron bases importantes para las alianzas que se posteriormente se producirán en 2002, las cuales fueron resumidas tras los seis puntos que planteaba el CDP:

1) el pedido de derogación de la ley 1.615 que posibilita la privatización de las empresas estatales,

2) oposición al proyecto de reforma de la Banca Pública,

3) contra el proyecto de ley Antiterrorista pedido por Estados Unidos y promovido por el Partido Colorado en el Congreso guaraní,

4) contra el proyecto de Ley de Concesión de Rutas,

5) contra el IVA agropecuario, y

6) que se termine la corrupción y la impunidad.

Aunque lejos estaban todavía las organizaciones del CDP de poder consensuar un programa alternativo de poder (de todas maneras ya se perfilaban algunas líneas y proposiciones comunes), las movilizaciones conjuntas consiguieron la obtención de los primeros cinco puntos exigidos ${ }^{16}$ y forzaron una experiencia colectiva de lucha, considerada el primer paso hacia una modificación radical de las estructuras de poder y la unificación de las clases subalternas tras objetivos e instituciones compartidas. La alianza temporal, a su vez, con los gremios obreros paraguayos y con otros sectores sociales, lograba hacer tambalear el gobierno 
de González Macchi y preocupar a Estados Unidos, quien veía en este paso el peligro de perder poder de operación sobre el cono sur. Por lo tanto, en ese periodo, las movimientos campesinos guaraníes logran consolidar "un caótico conjunto de reivindicaciones"17 que condujeron a la movilización de diferentes sectores de las clases oprimidas, tanto del campo como de la ciudad, poniendo en serias dificultades a las estructuras tradicionales e instalando un pensamiento contrahegemónico que cuestionaba la ideología de las clases dominantes, así como su capacidad de liderazgo. La experiencia compartida de lucha y los aprendizajes en las clases subalternas fue percibida como en extremo peligrosa por los sectores tradicionales de poder. Percepción confirmada siete años después si se tiene en cuenta el rol importante que los liderazgos campesinos jugaron en la reciente caída del Partido Colorado y en la victoria de Fernando Lugo. A pesar de que, por su poca experiencia en el 'juego institucional', no pudieron traducir esta capacidad de movilización en el ingreso de sus candidatos -algunos muy prestigiados como Belarmino Balbuena- en el Congreso Nacional guaraní. En este sentido, podría pensarse como tareas pendientes a futuro la instalación de una estrategia intramovimientos que aborde el espacio institucional como espacio de lucha y disputa por el poder.

Pero regresando al estado de rebeldía que se vivía en 2001, el mismo debe situarse en un contexto regional que propiciaba la conmoción en las clases dominantes (tanto guaraníes como estadounidenses) y que era el siguiente: en diciembre de ese año la movilización masiva en Argentina había forzado la renuncia del presidente Fernando de la Rúa y de su ministro de Economía (todo un símbolo de las políticas neoliberales de los años noventa), Domingo Cavallo, constituyéndose por entonces diversas organizaciones denominadas "asambleas barriales" que, en acciones compartidas con los movimientos de trabajadores desocupados y diferentes sectores gremiales y partidos de izquierda, mostraban una situación de crisis sistémica y de gobernabilidad. Mientras que en Brasil, en 2002, ganaba las elecciones (apoyado en una alianza de gremios y movimientos sociales como los sin tierra reunida en el partido de los trabajadores, PT) el sindicalista Luis Inacio Lula da Silva. También fracasaba un golpe de Estado contra el democráticamente electo presidente de Venezuela Hugo Chávez, quien acusó a Estados Unidos de conspirar para su derrocamiento y llamó, en enero de 2003, a construir el socialismo del siglo XXI apoyándose en una unión regional antiimperialista sudamericana. Mientras que en octubre de 2003, la movilización boliviana conocida como "la guerra del gas" forzaba la salida de empresas trasnacionales de ese país y la renuncia del neoliberal Sánchez de Losada, anticipando ya la llegada al poder del dirigente del Movimiento Hacia el Socialismo Evo Morales, quien se pronunciaba claramente contrario a los intereses y planes de Washington. Por esa fecha además 
se presagiaba la llegada del Frente Amplio (espacio político liderado por viejos izquierdistas, sindicatos y movimientos sociales) a la presidencia de Uruguay. En este marco no es de extrañar que la constitución del CDP paraguayo fuera interpretada como una amenaza por los sectores poderosos, los cuales decidieron operar de manera drástica permitiendo la intervención militar directa de Estados Unidos en co-participación con las Fuerzas guaraníes para restablecer el orden social.

\section{La reacción frente a la crisis y la institucionalización de las "salidas" milita- rizadas}

En consecuencia, tanto los grupos de poder locales como la administración republicana decidieron priorizar la denominada 'gobernabilidad' a partir del reforzamiento de las estructuras represivas de los aparatos del Estado (sumada al incremento de la para-militarización en ciertas áreas rurales), en tanto esta 'crisis orgánica' guaraní coincidía temporalmente con un clima internacional de temor y con el auge de la lucha antiterrorista promovida por el presidente G. W. Bush luego de los atentados del 11 de septiembre de 2001. La administración republicana encontraba, en consecuencia, la "oportunidad histórica" para profundizar, a través de instituciones y regímenes internacionales como la Organización de Estados Americanos -OEA, de la reactivación de pactos como el Tratado Interamericano de Asistencia Reciproca -TIAR, y de acuerdos binacionales como los que se terminarían realizando con Paraguay, algunas tendencias en materia securitaria a nivel hemisférico que ya se venían delineando desde la década del noventa (y que en realidad han operado -con diversos matices- en el continente desde los tiempos de la doctrina Monroe ${ }^{18}$ ). Éstas encontrarán un eco positivo en el Estado paraguayo que (al igual que el Estado colombiano) se alineará detrás de las propuestas de Washington, emitiendo una serie de normativas nacionales (inspiradas en las 'recomendaciones' de la potencia hegemónica) para la lucha contra las denominadas "nuevas amenazas" que asolan la post guerra fría y el reforzamiento de los mecanismos de disciplinamiento social. El Poder Ejecutivo guaraní consideró necesario realizar un acercamiento estratégico con el gobierno estadounidense, con el fin de permitir la finalización del mandato de González Macchi previsto para el 2003. También incidió en esta decisión gubernamental el hecho de que la dirigencia paraguaya -influenciada por la existencia de una burocracia estatal en la que persisten prácticas autoritarias ${ }^{19}$, de manera paradójica, esperaba poder fortalecer por medio de los acuerdos con la potencia del norte su posición dentro del Mercosur. Aspecto que evidenció la permanencia y resurgimiento del síndrome de país amenazado por sus vecinos (que encuentra su explicación en la historia paraguaya, en especial en los efectos devastadores de 

al nuevo escenario político

la Guerra de la Triple Alianza (1865-1870) y la Guerra del Chaco contra Bolivia (1932-1934)), y que debe considerar también las contradicciones entre la influencia estadounidense y la dinámicas de Seguridad sudamericanas caracterizadas por las luchas para obtener la hegemonía regional entre países como Brasil y Argentina, impresión que ni siquiera la ideología de la 'cooperación hemisférica' de los años noventa pudo extirpar. Este sentimiento de la 'clase política' paraguaya, unido a una tradición de colaboración militar con Estados $\operatorname{Unidos}^{20}$ y a la necesidad de asegurar su permanencia en el poder, resultará beneficioso para la administración republicana, la cual, apoyándose en la tesis que afirma que los lugares donde los 'Estados débiles' (como el guaraní) no tienen control y resultan propicios para organizaciones terroristas (y en coincidencia con la mirada estadounidense de que la fragilidad de la estructura estatal impide garantizar el ejercicio del monopolio legitimo de la violencia sobre determinadas áreas del territorio habilitando así un posible aumento 'contagioso' de la inestabilidad regional), el gobierno de G. W. Bush justificará su intervención en Paraguay. La Casa Blanca exigirá como contrapartida por su ayuda al Partido Colorado, el apoyo del gobierno guaraní en la lucha antiterrorista. Apoyo que se traducirá en varias medidas estatales de las cuales nos interesa destacar la legislación nacional en materia de Seguridad y mencionar la posición de la diplomacia paraguaya en los foros internacionales de la OEA.

Por lo tanto no debe sorprender que el 17 de septiembre de 2001, el gobierno de González Macchi permitiera el arribo a Paraguay de un avión estadounidense con 40 funcionarios del FBI en busca de miembros de la red Al Qaeda ${ }^{21}$, o que se realizaran detenciones de comerciantes de origen árabe en Ciudad del Este ${ }^{22}$, o que la postura de su canciller en la reunión de Cancilleres del 18 de septiembre de 2001 de la OEA fuera la de reactivar el TIAR para darle todo el apoyo a Washington en la lucha contra las 'nuevas amenazas'. Sin embargo, un hecho a destacar es que este Estado Sudamericano expresará que las Fuerzas Armadas Nacionales se encuentran -a partir de ese momento- en guerra contra el terrorismo, citando de manera explicita la Resolución 1.337 del Consejo de Seguridad de Naciones Unidos que afirma: "Los Estados miembros se encuentran obligados a combatir las nuevas amenazas, contra la paz y seguridad en el Orden, lo que implica estar en alerta y en guerra contra las fuerzas irregulares que ponen en peligro los fundamentos no solo del Estado de Derecho, sino los fundamentos mismos de nuestra civilización". ${ }^{23}$

Este pronunciamiento, diferente a las declaraciones del resto de los gobiernos de la región, tuvo como consecuencia efectiva que las leyes militares pasaran a tener primacía en el país. Lo que implicaba priorizar la competencia de la Justicia Militar por sobre la ordinaria, además de habilitar la total libertad de las mismas en actuaciones dentro del territorio nacional. De la sanción del Código Penal en 1997 y del Código Procesal Penal en 1998, delineados en la Constitución 
Nacional de 1992, hasta su modificación votada por la Cámara de Diputados el 3 de mayo de 2007 para introducir el delito de 'terrorismo' en el capitulo titulado "Hechos Punibles contra los Pueblos"24 (que todavía espera la media sanción de la Cámara de Senadores para entrar en vigencia), se fueron promulgando una serie de decretos del Poder Ejecutivo y de leyes aprobadas por el Congreso en el contexto histórico descrito. También se implementaron acciones tendientes al trabajo coordinado del Ministerio Público con las Fuerzas represivas, así como la participación de la ciudadanía en materia securitaria, por ejemplo a través de las Comisiones de Seguridad Ciudadana .

Definiremos a las políticas públicas dentro del marco normativo guaraní (caracterizado por un 'Estado de legalidad parcial', en tanto no alcanza aún las condiciones mínimas propias de un 'Estado de Derecho'25) que incluye:

1) el "Plan Nacional de Prevención del Delito y Seguridad Ciudadana de Paraguay" que comienza en 2001, bajo la administración de Oscar Germán Latorre, Fiscal General del Estado; y el "Plan piloto de la zona Sur de Limpio" de 2002: El primero constituirá una de las primeras políticas públicas paraguayas en materia de Seguridad influenciada por un nuevo paradigma que se venia instalando en este área desde los años ochenta. El mismo expresa que la prevención del delito aparece cada vez mas diferenciada del recurso penal (la tradicional idea de la finalidad preventiva y disuasiva de la pena) ${ }^{26}$, y por lo tanto la 'prevención' se instala como centro de las normas dictadas en esa materia. El mismo es presentado hasta la actualidad como una respuesta al creciente sentimiento de inseguridad que manifiesta la población debido al aumento de los índices delictivos, pero se genera un importante debate sobre jurisdicciones y la competencia del Ministerio Publico para su diseño e implementación ${ }^{27}$. El Plan fue pensado a partir de tres ejes centrales: a) participación ciudadana, organizada a través de asociaciones vecinales; b) estrategias de prevención integrada del delito, combinando los modelos de prevención situacional (ambiental y social) y; c) modelo de gestión multiagencial-por medio del trabajo conjunto del Ministerio Publico (y creación de fiscalías zonales y 'agentes fiscales de prevención del delito' bajo la orbita de la Fiscalía General del Estado, algunas de cuyas funciones son coordinar acciones con comisarías locales y realizar operativos de control), la Policía Nacional, y comisiones barriales. Algunos autores consideraron que este Plan reconoce su antecedente mas próximo en el programa de seguridad democrática del presidente colombiano Uribe Vélez, e interpretan que las verdaderas intenciones del mismo son: por una parte, recopilar información sobre la población local por medio de censos y entrevistas; y por el otro, legalizar como método la delación, que apunta a romper el tejido social y a sembrar desconfianza entre los propios $\operatorname{vecinos}^{28}$, para imputarle delitos a todo aquel ciudadano o ciudadana que presente 
comportamientos considerados 'subversivos' 29 . Por lo tanto, la implementación de esta especie de planes 'anti-criminales' en las ciudades de Capiatá, Coronel Oviedo, Caaguazú, Villarrica, Aregua, Mariano Roque Alonso, Lambaré, y en la zona de Zeballos Cué, las residencias de Asunción y Fernando de la Mora, debe ser analizada, como ya se dijo, en un contexto internacional signado por el temor. Clima que también es influenciado por el auge de corrientes como la de la tolerancia cero ${ }^{30}$ promovidas por fundaciones, el Manhattan Institute y la Heritage Fundation, y por medio de personajes neoconservadores estadounidenses como Lawrence Mead, William Bratton, y Rudolph Giuliani, y a partir del protagonismo de figuras influyentes como William Kristol y Robert Kagan - editores de la revista The Weekly Standard -o como Charles Krauthammer, Lawrence Kaplan, Robert Kaplan $^{31}$ y otros. Todos ellos pregonan la necesidad de acudir a la fuerza militar para promover una 'cruzada democrática' en el mundo que imponga los valores morales estadounidenses a escala mundial. La retórica militar de la 'guerra' contra el crimen y de la 'reconquista' del espacio público que asimila a los delincuentes reales o imaginarios -, los pobres, los jóvenes, los sin tierra, los sin techo, y otros sectores marginales, a 'invasores extranjeros' (a elementos externos y enfermos que es imperativo evacuar del cuerpo social), ha encontrado un eco en varias ciudades del mundo que proponen soluciones represivas asociadas a una concepción de 'limpieza social' que solo devienen en un incremento de la violencia y traslada hacia las Policías y Fuerzas de Seguridad una competencia que debiera pertenecer estrictamente al ámbito de las políticas sociales. Dirigentes de los movimientos campesinos $^{32}$ denunciaron que este tipo de políticas securitarias desarrolladas en Paraguay tienen por objetivo la legalización del accionar represivo del Estado sobre los lideres de las organizaciones del campo, quienes son presentados como terroristas, al mismo tiempo que propician la complicidad entre instancias judiciales (cuyas instituciones a su vez se caracterizan en Paraguay por la superposición de funciones, la discrecionalidad burocrática, la falta de independencia y de capacidad de control sobre el poder político, y por un alto nivel de corrupción ${ }^{33}$ ), la Policía y las Fuerzas Armadas, en actos penados por los tratados internacionales en materia de Derechos Humanos (como la privación ilegitima de la libertad o la tortura). Definitivamente este aspecto de las políticas públicas de Seguridad, que comprende la reforma de la Justicia paraguaya y la vinculación inter-agencias estatales, así como el involucramiento de la población civil en este tipo de tareas promoviendo conductas insolidarias en el tejido social, resulta sumamente complejo y abre una línea de investigación a desarrollar en el futuro.

2) los Decretos del Poder Ejecutivo Nacional 17.370 y 17.855, 17.855, 17.870, y 167: A comienzos del mes de mayo la red de organizaciones campesinas nucleadas en el CDP, llamó a la ciudadanía a manifestarse el 1 de junio del 2002 
en contra de la ya mencionada ley que establecía la privatización de los entes públicos. Frente a la magnitud de las manifestaciones que se esperan para esa jornada el Presidente paraguayo dictó el decreto 17.370 (del 31 de mayo de 2002) que disponía la movilización de las Fuerzas Armadas en cooperación con la Policía Federal para evitar cierres de ruta y supuestos atentados. Lo llamativo del decreto -además de sentar un precedente legal respecto al rol de las Fuerzas Armadas en tareas de Seguridad Interior- era su retroactividad al 30 de mayo, interpretada como maniobra para dar presunta legalidad a las tareas que el Ejército se encontraba realizando en el departamento de San Pedro, atemorizando campesinos con la intención de impedir su participación en las jornadas del 1 de junio ${ }^{34}$. El día 5 se produjo la muerte del dirigente rural Calixto Cabral a causa de un disparo policial, se multiplicaron las protestas, lo que devino finalmente en la derogación de la ley de privatizaciones y la concesión de cinco de los seis puntos exigidos por el CDP y los manifestantes. Sin embargo, ese mes, así como todo el periodo del año 2002, seria considerado un momento clave respecto a los cambios de roles de las Fuerzas Armadas, en tanto que a partir de entonces se las utilizará de manera permanente no solo como elemento activo, sino también disuasivo, al interior de las fronteras nacionales. Otro hecho fundamental para comprender el giro en la legislación será la desaparición y posterior asesinato de Juan Francisco Arron y Anuncio Martí, a quienes se vinculaba con el secuestro de Maria Edith de Debernardi, cuando en realidad los movimientos populares responsabilizaron por la misma a altos mandos de la Policía Judicial y al gobierno de González Macchi. Este hecho trajo aparejadas una serie de manifestaciones en reclamo del esclarecimiento del caso, momento que fue aprovechado por los seguidores del General Lino Cesar Oviedo (el 14 de julio de 2002) para exigir la renuncia del presidente del Paraguay. Como respuesta a la multiplicación de las acciones de protesta y a algunos actos de vandalismo, el 15 de julio González Macchi promulgó dos decretos: el 17.855, cuyo artículo 1 expresaba: "Dispóngase el empleo de elementos y otros medios de las Fuerzas Armadas de la Nación para cooperar con la Policía Nacional en el mantenimiento de la Seguridad interna (...)" ${ }^{35}$ Y el 17.870 que establecía el estado de excepción, lo que habilitaba al presidente a asumir todos los poderes y suspender varias garantías constitucionales (con la salvedad del habeas hábeas). Durante la vigencia de estas normas fueron encarceladas provisoriamente 182 personas, aunque casi todos los decretos de detención de estos ciudadanos fueron dictados posteriormente a las mismas, una práctica que se tornaría habitual durante los años siguientes ${ }^{36}$.

A lo largo de 2002, también se registró presencia militar estadounidense -114 efectivos- en suelo paraguayo, la que organiza 16 misiones $^{37}$ - un promedio de 1,3 ejercicios por mes, que se dividen entre operativos MEDRETES ${ }^{38}$ o de atención medica y odontológica a la población, en especial en el interior del país, 
por ejemplo en la zona del Chaco, así como ejercicios militares de otra índole y seminarios de formación antiterrorista para tropas guaraníes y de la región. En el mes de octubre el General Hill, titular del Comando Sur del Ejército de Estados Unidos, realizó una visita para entrevistarse con el Presidente, el Canciller, y el Ministro de Defensa de la República del Paraguay, con el fin de insistir respecto a la necesidad de crear una fuerza antiterrorista en la zona de la Triple Frontera donde, según este funcionario, se encontraban células de grupos terroristas. Esta exigencia se inscribe en la línea de las representaciones estratégicas ${ }^{39}$ estadounidenses a partir de las cuales el espacio geográfico se libera de las fronteras físicas delineadas por la geopolítica tradicional ${ }^{40}$, redefiniéndose la territorialidad a partir de la mirada securitaria de la potencia hegemónica que se expresa particularmente en determinadas áreas, apuntando al control (por ejemplo, no solo del flujo poblacional sino también en materia de informaciones) sobre la supuesta 'permeabilidad' de las zonas fronterizas.

El 15 de agosto de 2003, asumió la titularidad del Poder Ejecutivo el nuevo Presidente (candidato también del tradicional Partido Colorado) Nicanor Duarte Frutos. La cantidad de ejercicios militares ese año ascendió a 20 y se registró la presencia de 133 efectivos estadounidenses. A pocos meses de su última visita regresaba el general Hill para verse con el nuevo gobierno e insistir en un acuerdo de inmunidad que impidiera que el Estado paraguayo pudiera iniciar acciones, en caso de que el personal estadounidense cometiera algún delito durante los ejercicios militares, bajo el artículo 98 del Estatuto de Roma en la Corte Penal Internacional ${ }^{41}$. El 27 de agosto, el presidente Duarte Frutos publicó el Decreto 167 titulado "Por el cual se dispone la tarea conjunta de los miembros de la Policía Nacional y las Fuerzas Armadas de la Nación, con la finalidad de garantizar la seguridad interna" ${ }^{42}$ el cual, según testimonios de dirigentes de los movimientos rurales, habilitará mayores niveles de represión en el campo y desalojos violentos, al tiempo que le daba un giro definitivamente permanente a la tarea de las conjunta de militares y policías que había comenzado en 2002.

3) la Resolución 503 de la Cámara de Senadores ${ }^{43}$, y las leyes 1337/99, 2447/04, 2594/05: Para el año 2004, aunque se mantuvieron la cantidad de ejercicios militares - 20 - se multiplican las visitas de los altos mandos del Ejército de Estados Unidos a Paraguay con el fin de insistir en los pedidos de inmunidad para sus tropas. En marzo llegó al país el general Richard Myers, Jefe del Estado Mayor conjunto de Estados Unidos, y al poco tiempo el encargado -símbolo de la administración republicana de G.W. Bush- de Asuntos del Hemisferio Occidental de la Casa Blanca, Otto Reich. Ambos exigieron la firma de un nuevo convenio bajo la amenaza de retirar la ayuda económica militar al Estado guaraní. ${ }^{44} \mathrm{Al}$ poco tiempo de la partida de los funcionarios estadounidenses se publicaron la firma 
de 'notas reversales' que posteriormente (gracias a la aprobación del Congreso paraguayo el 18 de junio) se convertirán en la ley 2.447 cuyo texto dispone:

Una lista parcial de ejercicios, seminarios, conferencias e intercambios militares bilaterales y multilaterales que se realizaran en La Republica del Paraguay desde el 10 de julio de 2004 hasta junio de 2005 con la participación de miembros de las Fuerzas Armadas de los Estados Unidos de América (...) El gobierno de la Republica del Paraguay otorgara a todo el personal estadounidense asignado al ejercicio de referencia, que se encuentre en territorio paraguayo y por el periodo de tiempo que dure el mismo, una categoría jurídica equivalente a aquella otorgada al personal administrativo y técnico de la Embajada de Estados Unidos de América (...) El personal estadounidense podrá salir e ingresar al territorio paraguayo con documentos de identificación de los Estados Unidos y autorizaciones de viajes individuales o colectivas (...). ${ }^{45}$

Esta legislación debe ser analizada como expresión de los cambios en la normativa de Seguridad que la potencia hegemónica busca generalizar en todo el continente y en especial en el cono sur, donde se modifican las concepciones de las Fuerzas Armadas latinoamericanas respecto de su misión histórica y de la guerra, que pasa a actuar como disciplinadora de mercados, de competidores, pero sobre todo de rebeldes. Operando entonces lo militar como eje ordenador frente a la indisciplina popular, que se expresa de maneras diversas e intempestivas por fuera del espacio 'tradicionalmente' estatal. La visión del campo de batalla se impone así como forma de relacionarse socialmente, producto de la incapacidad real del capitalismo (en el actual momento histórico) de ofrecer una propuesta de vida al conjunto de la población mundial. ${ }^{46}$ En tanto, como afirma Foucault, la atomización social es el caldo de cultivo de la dominación ${ }^{47}$, pero también de la insubordinación, la ampliación de los desplazados o excluidos de algún contrato social ${ }^{48}$, quienes son arrojados de manera brutal a una suerte de estado de naturaleza hobbesiana ${ }^{49}$, conduce a su vez a la desestructuración de los vínculos comunitarios, provocándose manifestaciones de resistencia que, como aparece en el caso paraguayo, resultan el basamento social insurgente sobre el que se construirá la percepción de que la nueva amenaza es asimétrica ${ }^{50}$. Así es como se justificaron los métodos irregulares que contemplan las denominadas operaciones militares distintas a la guerra. Un ejemplo de este tipo es la llamada "contraguerra de redes sociales" 51 , concepto que utilizó la CIA, en el informe titulado "Tendencias Globales al 2015", para caracterizar los conflictos futuros que pueden sobrevenir en el hemisferio. Basándose en la experiencia del zapatismo mexicano, la agencia estadounidense expresaba la necesidad de controlar el accionar de movimientos indígenas que contarían con la ayuda de "redes internacionales de activistas 
defensores de los derechos indígenas y bien organizados grupos de derechos humanos y ambientalistas". ${ }^{52}$ La insistencia de Estados Unidos sobre la zona de la Triple Frontera puede ser pensada a partir de la potencialidad de este punto de encuentro geográfico para el proyecto Mercorcur, en tanto área de conexión natural entre las dos naciones económicamente más relevantes de Sudamérica: Brasil y Argentina. Por lo tanto, Ciudad del Este constituye un espacio que multiplica las posibilidades de tránsito irrestricto entre los países y que se convierte en zona propicia para la propagación de vínculos (solamente enturbiados por las guerras del pasado) que darían a cualquier proyecto integrador regional anti-hegemónico, el carácter de sancionadores de realidades potencialmente revolucionarias debido a la progresiva profundización de las prácticas cotidianas. ${ }^{53}$ En consecuencia, no es de sorprender que desde antes del 2001 los altos mandos militares estadounidenses y las agencias de inteligencia se encontraran interesados en tener posiciones seguras y permanentes en este área ${ }^{54}$, que además de su inmensa riqueza natural (en especial por ser punto de recarga de una de las reservas potables de agua dulce mas grandes del mundo, el Sistema Acuífero Guaranín ${ }^{55}$ ) es percibida como clave para desactivar cualquier proyecto entre los países de la zona que prescinda de la mediación de Estados Unidos, en especial si va en sentido contrario a sus intereses en el Hemisferio, como ser la firma del ALCA o la ideología del libre comercio. El discurso que enarbola la lucha contra el terrorismo y las drogas, y que promueve el control sobre lo que se denominan 'fronteras porosas', debe ser estudiado en el marco del proyecto de Washington de crear un nodo centralizador de información ${ }^{56}$ que podría ser utilizada por la potencia hegemónica en función de sus necesidades. Por eso se insiste en que los registros de tránsitos internacionales -a partir de los códigos en los pasaportes- alimenten esta gran base de datos pensada al servicio de la guerra y de la seguridad estadounidense. ${ }^{57}$ En este sentido la legislación paraguaya también posibilita el acceso sin control al país de cualquier tipo de elemento que pudiera servir para los fines de montaje de centros de búsqueda de datos e información, tanto del lado oeste en la frontera con Bolivia ${ }^{58}$, como en la localidad de Juan Pedro Caballero ${ }^{59}$, situada cerca de la frontera con Brasil.

En esta línea opera la Ley 2.594 -aprobada el 5 de mayo de 2005-, que, además de conceder inmunidad jurídica al personal estadounidense desde junio de 2005 a julio de 2006 "Otorgará igualmente liberación aduanera sobre la importación y/o exportación, así como exención de inspección e impuestos locales para los productos, propiedad y materiales para, o en representación del personal de los Estados Unidos asignado para realizar este ejercicio". ${ }^{60}$

Mediante las medidas exigidas, Estados Unidos encuentra la posibilidad de poner trabas a un proyecto de integración sudamericana, que a pesar de sus muchas limitaciones, no estaba -ni está- aun desarticulado. Proyecto que no solo 
resulta importante en materia de acuerdos económicos, sino también frente a la posibilidad de integración energética (demostrado más que nunca a partir de las propuestas planteadas por el presidente Hugo Chávez para el Mercosur y los intentos de replantear los precios y la administración de los recursos energéticos de Itaipú principalmente entre Brasil y Paraguay), de posible gestión de los recursos naturales de la zona, y en cuestiones de control migratorio. Este último resulta un tema no menor en materia de potencialidad política, en especial en Paraguay, país signado por procesos de migración y exilio que, en determinadas épocas históricas, forzó a camadas de dirigentes a utilizar estratégicamente esta dinámica para organizar y promover movimientos revolucionarios desde los países limítrofes. No son casuales, aunque si excepcionales, las limitaciones constitucionales en materia de derechos políticos de los migrantes, así como tampoco el sistemático cierre de fronteras en periodos electorales. La aparición de la migración como nueva amenaza en la lista de las representaciones estadounidenses, se traduce también en una reafirmación del unilateralismo del norte en la región. La cual se consolida por medio de la firma de acuerdos bilaterales con Estados como el paraguayo, poniendo en evidencia, una vez más, las grandes líneas sobre las que se estructuran los debates estratégicos después de doscientos años, y que perduran a pesar de los cambios en el sistema internacional. Por un lado la posibilidad del viejo sueño bolivariano de integración del continente y de afirmación de una identidad latinoamericana o sudamericana que, con contornos imprecisos, resurge regularmente. Las integraciones regionales de los últimos tiempos como el Mercosur o el $\mathrm{ALBA}^{61}$, buscarían inscribirse en una lógica emancipatoria frente a la potencia hegemónica. Mientras que, por otro lado, Estados Unidos, mezclando un espíritu mesiánico con ansias de dominación- pretende consolidar de manera definitiva la fórmula resumida en la célebre frase "América para los americanos".

Claro que la conceptualización estratégica estadounidense sobre los riesgos de estas áreas fronterizas descriptas como 'zonas ingobernables' (favorecidas por el factor geográfico y por no encontrarse totalmente integradas al territorio nacional), las cuales supuestamente 'forzarían' la intervención de la potencia hegemónica y la subordinación de la soberanía en su sentido tradicional en beneficio de una promocionada seguridad continental, presenta un fenómeno especial: Estados reconocidos por la comunidad internacional y organizados legítimamente permitirían el desarrollo de actividades ilegales, asumiendo una posición cómplice que se constituye como enlace institucional de 'protección' hacia los grupos o actores que desarrollan actividades ilícitas en el territorio. Por lo tanto, el reparto de las ganancias a nivel de funcionarios públicos obtenidas por las actividades clandestinas en estos lugares fomenta los niveles de corrupción y actuaría de manera funcional respecto de las tendencias donde determinados 
actores trasnacionales buscan nuevos lugares para desarrollar negocios sumamente rentables. Mas que una 'ausencia' estatal, entonces se registran problemas de tipo estructural asociados a conductas oficiales corruptas (influidas por redes mafiosas), que junto con las dificultades de algunos Estados latinoamericanos para controlar el territorio, debe ser analizada en relación con los efectos de las políticas neoliberales implementadas durante los años noventa, con déficit históricos en materia institucional (en especial de control y organización de la administración pública), y con la cultura política y las practicas heredadas de otros tiempos, las cuales son el basamento sobre el que se constituyó lo que podríamos denominar un Estado Mafioso, con el cual deberá lidiar el próximo gobierno de la APC. Al mismo tiempo, las orientaciones estratégicas tomadas por Paraguay, deben pensarse insertas en marcos mas complejos donde también inciden otras variables, y donde afloran a su vez espacios de tensión y resistencias como las expresadas en el I y el II Foro Social de la Triple Frontera, o en las posiciones de gobiernos como el brasileño (que niega las nociones de 'Estados débiles' de 'erritorios ingobernables' o que la Triple Frontera sea una base terrorista, y refuerza el derecho de los Estados a ser «guardianes soberanos» de los recursos naturales como la Amazonia). Algunas de las cuales, así como los diferentes matices respecto a las posturas de los gobiernos de Brasil, Argentina, Uruguay y Paraguay, también se expresaron en la Conferencia Especial sobre Seguridad Hemisférica realizada en Monterrey en 2003. La posición de la diplomacia guaraní en foros de la OEA como éste, es importante para comprender las consecuencias del nuevo concepto securitario que, al final de la reunión de México, se presentaba públicamente en la Declaración Sobre Seguridad Hemisférica en las Américas.

Este documento amplió la definición tradicional de Seguridad de los Estados a partir de la incorporación del texto titulado "nuevas amenazas, preocupaciones, y desafíos", que incluía aspectos políticos, económicos, sociales, de salud y ambientales en un mismo paquete:

Terrorismo, delincuencia organizada trasnacional, el problema mundial de las drogas, la corrupción, el lavado de activos, el trafico ilícito de armas y las conexiones entre ellos; Pobreza extrema y exclusión social de amplios sectores de la población, que también afectan la estabilidad y democracia..., erosiona la cohesión social y vulnera la Seguridad de los Estados; los desastres naturales y los de origen humano, el VIH/SIDA y otras enfermedades, otros riesgos a la salud y el deterioro del medio ambiente; la trata de personas; los ataques a la seguridad cibernética; la posibilidad de que surga un daño en el caso de un accidente o incidente durante el trasporte marítimo de materiales potencialmente peligrosos, incluidos el petróleo, material radiactivo y desechos tóxicos; y la posibilidad de 
acceso, posesión y uso de armas de destrucción en masa y sus medios vectores por terroristas ${ }^{62}$.

Es evidente el peligro de regresar a una concepción totalizadora de la Seguridad tal como fue, en tiempos de las dictaduras militares (con su particular énfasis en la contrainsurgencia y el combate contra el enemigo interno), debido a la extensión del concepto 'multidimensional' lacual constituye un riesgo de aumento de la 'seguritizacion'de los problemas de la región y, por consiguiente, habilitador de la 'ilitarización'como una respuesta para confrontarlos.

Esto sucedió gracias a la tendencia histórica de intervención política de las Fuerzas Armadas durante los regímenes denominados por O’ Donell “burocráticosautoritarios" (o en el contexto de conflictos armados o de inestabilidad social); por la posición estadounidense sobre el combate contra las drogas (que se promovió desde fines de los ochenta, y que continua propiciando un rol mas amplio de las Fuerzas Armadas en el cumplimiento de la ley con efectos bastante cuestionables en materia de derechos humanos); las crisis de los sistemas de seguridad pública que padecen la mayoría de los países del continente; y en especial debido a la "guerra contra el terrorismo" lanzada por Estados Unidos que instaló una definición expansiva (pero bien poco clara) del terrorismo aumentando la "responsabilidad" de combatirlo por las Fuerzas militares mediante cualquier forma que éstas consideren que se exprese. Ninguna de las declaraciones de los futuros candidatos presidenciales estadounidenses hace pensar que esta actitud se modificará en el futuro. Los debates solo se centran en torno al retiro de las tropas de Irak, mas que a la ideología de fondo que sustenta su presencia en Medio Oriente u otras partes del mundo. La publicación del texto de la OEA evidencia un modo riesgoso de asociar los problemas de desarrollo con amenazas a la Seguridad, una especie de "seguritizacion de la agenda del desarrollo", que presentaba una única manera -ineficaz e inapropiada- de resolver una amplia gama de problemáticas bien diversas. Aspecto que, por otra parte, genera las condiciones para justificar el uso y abuso de las Fuerzas Armadas en misiones que -tradicional y formalmente- no le corresponden.

Puesto que las diversas formas que toman los conflictos violentos ensanchan al máximo la inexistencia de fronteras entre combatientes y no-combatientes, e incluso el tradicional paradigma de soberanía interpela a una nueva noción de la misma, la cual (según Estados Unidos) debe subordinar la soberanía nacional en favor del carácter "global" de la Seguridad, fundamentándose en las características trasnacionales de los riesgos. Esto implicaría revisar la relación entre una nueva territorialidad que entra en conflicto con la idea de la frontera como límite nacional de poder y control soberano, ubicándose entonces a los espacios fronterizos frente a una paradoja: cuanto mas se convierten en prioridad estratégica para 
el imperialismo en el actual momento capitalista (en el contexto de un sistema internacional de control al que se presenta supuestamente desnacionalizado ${ }^{63}$ ), mas devienen en ámbitos de tensión, conflicto, y sobre todo resistencias, frente a una normativa que instala en el debate el poder tradicional del Estado Nacional ${ }^{64}$.

En esta línea debe pensarse la posición geoestratégica de Paraguay, que se encuentra atravesado por dos ejes del proyecto de Integración de la Infraestructura Regional Sudamericana, mas conocido como IIRSA. ${ }^{65}$ Si bien la postura de países como el guaraní, de adopción de cierta normativa, respondió a gestos políticos de alineamiento con Washington, también es posible que los mismos se debieran al objetivo de captar atención y recursos financieros de agencias estadounidenses para problemas sociales y ambientales -como la USAID- (además de la búsqueda de un nuevo rol para las Fuerzas Armadas, en cierta medida desprestigiadas por su accionar durante las dictaduras).

El gobierno paraguayo de Duarte Frutos, en este sentido, se declaró en 2003, a favor de que se sumaran y fortalecieran instrumentos jurídicos como la Convención Interamericana contra el Terrorismo, mientras que también apoyó el aumento de atribuciones a la Junta Interamericana de Defensa pedido por la Casa Blanca para combatir las nuevas amenazas. En esta línea, no compartirá los tibios intentos de sus vecinos por diferenciar los ámbitos de la Defensa de los de la Seguridad -cuando países como Brasil y Argentina pretendían que la ampliación de las definiciones promovida por el norte no diluyera la divisoria entre ambas, claramente contemplada en su legislación nacional-. El reciente nombramiento del Ministro de Defensa del futuro gobierno de la APC, mas que presentar una ruptura con Washington, intenta reforzar la idea difundida por Lugo durante toda su campaña de "un camino propio", y si se quiere, alejado del izquierdismo de Evo Morales y Hugo Chávez.

\section{Factores estructurales paraguayos: ¿explican su impronta aislacionista-de- fensiva?}

Frente a la pregunta sobre cuáles resultan los factores estructurales y profundos que posibilitan esta alianza con Estados Unidos, se destaca en este sentido la herencia de prácticas estimuladas sistemáticamente a lo largo de la historia por una concepción defensiva que ha resultado funcional a la militarización de las relaciones sociales, tanto por los conflictos de tierra asociados al latifundismo, la permanente obstrucción para una acumulación de tipo capitalista "clásica" al estilo latinoamericano ${ }^{66}$, o la inexistencia de un proyecto hegemónico de país -en el sentido gramsciano- por medio de un grupo cohesionado, que lograra pactar sus intereses particulares para luego revestirlos de una pretendida representación universal de todos los actores sociales logrando generar ciertas estabilidad política 
y social apoyada en un determinado marco instituciona $1{ }^{67}$. Este constituiría parte de otros factores que podrían haber exacerbado un aislacionismo defensivo funcional al tipo de recurso personalista y que marcaron a esta nación desde su mismo origen.

Varios de estos aspectos resultan importantes en tanto han condicionado, no solamente las estrategias de las elites políticas y de las clases dominantes paraguayas -haciéndolas más vulnerables a la incidencia estadounidense-, sino también la construcción de prácticas contra-hegemónicas al interior de las clases subalternas. La ofensiva militarizada (y para-militarizada) en el campo, y en menor medida, en los centros urbanos, respondió no solo a un reforzamiento del aparato represivo estatal guaraní apuntalado por la ideología securitaria estadounidense, sino que al mismo tiempo este hecho se facilitó en tanto se asentaba sobre una subjetividad modeladora de determinado tipo de conductas que afectaba al conjunto de la población, las cuales resultan (y ha resultado) funcionales a los intereses de diferentes fracciones de clases dominantes (ideologías y un tipo de sociabilidad que a su vez son estimuladas desde las diversas organizaciones ubicadas al interior de la sociedad civil como los medios de comunicación ${ }^{68}$ ). En este sentido, otro de elementos que nos interesa desarrollar para responder a la pregunta sobre cuáles son algunos de las claves que predisponen a una alianza con Estados Unidos y a la percepción de los países vecinos como una amenaza (exacerbando la impronta aislacionista defensiva), es cómo la misma se construyó a partir del efecto de las guerras del pasado.

Hay un aspecto menos trabajado en esta investigación pero que resulta preciso mencionar, el mismo refiere a rol una identidad guaraní (potenciada por la fusión aborigen-colonial, la cual le permitió su hegemonía sobre otras lenguas prehispánicas) que de alguna manera operó como principal fuerza unificadora de la nación y jugó una función integradora en Paraguay.

La relación entre la identidad guaraní y otras fuerzas históricas que predominaban en el país reforzaron un nacionalismo introvertido, que terminó operando de manera eficaz para las propuestas del norte, y que puede ser explicado a la luz de sus orígenes, pero que también amerita profundas reflexiones para pensar sus posibles impactos en la construcción política y organizacional de las clases subalternas.

Según la hipótesis desarrollada por Meliá69, la cultura autoritaria preponderante en Paraguay descansa en gran medida sobre el silencio tendido por encima de la cultura autóctona y sus derivados, y sobre el eco que ha llegado hasta nosotros. Ya veremos como este elemento se combinó también con las secuelas del terrorismo de Estado proyectándose hasta la actualidad.

Uno de los valores mas trascendentes de este legado es la pervivencia del 
uso de la lengua guaraní en la parte mayoritaria de la población (alrededor del 87\%) que refleja en una particular "voluntad de ser" (ñande reko), una actitud de prolongar y enriquecer, un modo particular de comprender la vida. En opinión de Meliá, el guaraní corresponde a una forma de vida indígena vivida por la sociedad paraguaya $^{70}$, en tanto la lengua actúa como un eje articulador de la identidad nacional.

Sin embargo -para este autor- otros ejes articuladores de esta identidad nacional serían su carácter campesino (koygua) y su pobreza (ñande mboreaju), los cuales aparecen estrechamente vinculados al pasado autóctono (al igual que la noción de tiempo no lineal, de espacio difuminado y sin límites, y de pertenencia mas que de propiedad, como proyección de un espacio que rebasa las fronteras y de un rechazo al principio de propiedad, heredados de los rasgos típicos de las sociedades cazadoras-recolectoras que poblaron estas tierras antes de la conquista española). Aspecto cultural que debe ser relacionado con las transformaciones provocadas por el paso de la propiedad comunitaria a la propiedad privada, y que pueden ayudar a comprender (y complementar, desde otro punto de vista) las dificultades y obstrucciones para un desarrollo capitalista a la manera "clásica" (así como la consolidación del ideario liberal de moda en los tiempos de las revoluciones criollas). Y en especial, podría devenir en segmento explicativo de la regla que persiste en materia de ocupación de tierras, acción considerada legítima por lo movimientos campesinos y método central de los mismos, sobre todo cuando aquellos que poseen y concentran la propiedad se niegan a dar parte a los que menos tienen. En un informe difundido por la Red Rural el 9 de mayo de 2008 , se afirma que las ocupaciones de tierra son legales y necesarias para que el gobierno tome consciencia de las necesidades del pueblo ${ }^{71}$.

Si el universo guaraní (que resulta eco lejano también de la influencia histórica de la encomienda hispánica, de las misiones jesuíticas, o de tradiciones migratorias al interior y fuera de Paraguay) puede ser interpretado como parte de reglas de comportamiento, valores, y sistemas simbólicos que "congelaron" la experimentación y los procesos de aprendizaje institucionales "modernizantes", resultado afines a un "tradicionalismo" sobre el que supieron apoyarse el Partido Colorado, dictadores, y determinado tipo de estructuras de poder, de igual manera podrían pensarse sus potencialidades libertarias en tanto exacerban las prácticas y el sentimiento de pertenencia a un colectivo, que podría jugar un rol unificador sobre las clases oprimidas constituyéndose como basamento de programas y niveles organizacionales e institucionales que planteen una alternativa revolucionaria en materia política, económica, cultural y social. En este sentido, los debates que se instalan actualmente en la literatura académica, estimulados por la caída del Partido Colorado paraguayo luego de 61 años en el poder, buscan realizar aportes a 
un proceso que, según algunos autores, es interpretado como el verdadero y tardío comienzo de una transición democrática (en tanto por primera vez se materializa una alternancia política de gobierno). En especial gracias a una combinación de crisis inter-burguesa, crisis de aparatos de dominación (Estado, Iglesia) y crisis socio-política ${ }^{72}$, aunque también de un largo proceso de construcción, activación, y recuperación identitaria, de las organizaciones de las clases subalternas.

Por el contrario, para otras investigadoras como Valeria Soler, los resultados electorales del 20 de abril de 2008 expresan un punto de arribo y no de partida de un proceso de transformación política iniciado en 1989 con el fin de la dictadura militar. El mismo evidenciaría una experiencia de identidades políticas que circulan por fuera de los partidos tradicionales y una ruptura con la mirada histórica construida por Strossner, quien impuso una identidad nacional que se amalgamaba a una identidad colorada (a partir de la estrategia de re-significar la figura de López y Francia como lideres colorados). En definitiva, se lee la victoria de este ex obispo, líder austero -tanto en su imagen como en su discurso-, como expresión de una crisis de representación política típica de la modernidad, que logra saldarse de manera paradójica, apelando a elementos y a representaciones no modernas de la sociedad paraguaya que logran capitalizarse políticamente por dentro de los marcos institucionales tradicionales.

Reflexionar sobre experiencias emancipatorias (como la del MAS en Bolivia y la organización del MST brasileño), en tanto producto de una "identidad en movimiento" reconstruida y re-significada a partir de las luchas históricas de diferentes sectores explotados transformada (luego de procesos con sus respectivas especificidades) en un proyecto político alternativo de poder, podría brindar dispositivos importantes para contribuir con propuestas unificadoras y potenciar lógicas de tolerancia y cooperación al interior de las clases subalternas paraguayas, y en especial entre los sectores mas radicalizados que conforman la APC. Los mismos podrían nucleares concretamente en torno a la Defensa de los puntos programáticos de la campaña de Lugo, intentando consensuar y avanzar en los debates sobre su implementación. Esto implica cuestionarse sobre otros elementos instalados en el imaginario colectivo del conjunto poblacional (y no solo de las elites políticas o de las clases dominantes), que tuvieron continuidad y se fueron profundizando con el tiempo -también potenciados por los efectos provocado por el terrorismo de Estado-, como ser el sentimiento de amenaza vecinal y el aislacionismo ${ }^{73}$, la marcada autosuficiencia en muchos aspectos (actitudes que tienen como complemento la desconfianza, el recelo, la valoración exagerada del camino propio $^{74}$, y el rechazo hacia todo lo que proviene del exterior), los cuales encuentran su explicación histórica en lo que significaron las guerras del pasado. Si muchas veces la mayor parte de la población guaraní delegó la responsabilidad 
organizativa del país en una fórmula personalista, avaló cierta tendencia hacia el autoritarismo ${ }^{75}$, la figura clientelar, y sobre todo la militarización de la política, fue porque consideraba necesario estar preparándose permanentemente para enfrentar la amenaza exterior.

Esta actitud logró trasmitirse de generación en generación y se remonta a mediados del siglo XVII, cuando la notable prosperidad económica de los jesuitas en territorio de tupi-guaraní colisionó con los poderes locales de Sao Paulo y con las colonias españolas en Paraguay (a quienes desfavorecía la imposibilidad de esclavizar a los indígenas). Desde ese periodo en adelante, la facilidad con que el territorio paraguayo era invadido desde el exterior dejó sus huellas en la memoria del pueblo. Por ejemplo, la Guerra de la Triple Alianza contra Brasil, Argentina y Uruguay $(1865-1870)^{76}$, no hizo sino consagrar este sentimiento aislacionista. En 1870, el conflicto bélico finalizó con una de las mayores hecatombes en la historia de la nación guaraní, y esta pesadilla vino a probar de modo definitivo en el imaginario popular que la agresión externa era un peligro real, mientras que al mismo tiempo actuó como una profecía auto-cumplida en la mente de los gobernantes paraguayos, que a partir de entonces cultivaron en exceso una actitud defensiva y quedaron prisioneros de ella.

A su vez, Paraguay no logró articular una acción diplomática permanente destinada a aprovechar las rivalidades entre sus vecinos y, ni siquiera, como último recurso, buscó aliarse a uno de ellos con el fin de repeler la amenaza del otro y del intervensionismo de otras potencias de la época que operaban a través de los Estados vecinos. Esta supuesta "irracionalidad diplomática" es explicada extrañamente desde la línea institucionalista como el resultado de una vida republicana que solo conocía largas dictaduras personalizadas ${ }^{77}$ como fórmula de orden ante las divisiones internas y los temores al exterior. Lo cierto es que la derrota en el campo de batalla pasó a alimentar con renovados bríos el mito nacional y heroico de la nación guaraní, capaz de los mayores sacrificios, odiada y envidiada por los demás países de la región, envilecida por la ocupación, pero siempre dispuesta a recuperar su sitial una vez que el mal momento pasara y apareciera un nuevo sucesor digno del osado presidente Francisco Solano López, muerto en combate.

Otro episodio histórico que vino a reforzar esta percepción y actitudes defensivas paraguayas fue la Guerra del Chaco ${ }^{78}$ contra Bolivia, y aunque la nación resultó vencedora ( a pesar de su inferioridad en equipamiento militar contra una Bolivia asesorada por Alemania) los costos fueron inmensos y el territorio quedó abandonado. La región recién ha logrado cierta atención en los últimos tiempos, clasificada como una nueva "zona gris" y "frontera porosa" por Washington, quien expresó un profundo interés y notables inversiones de dinero desde la agencia gubernamental USAID ${ }^{79}$ en la protección de ciertas áreas de recursos naturales 
a través de la financiación de ONGs locales, y por su posición geoestratégica circundante con una Bolivia presidida por Evo Morales que se expresa abiertamente contraria a los intereses estadounidenses en la región. La misma también ha resultado teatro de operaciones de varios de los ejercicios militares que organiza el Comando Sur, aspecto que no ha desatado el sentir nacionalista y opositor de la población paraguaya ni de sus elites políticas, las cuales perciben a la potencia hegemónica como mucho mas lejana, menos peligrosa (y hasta una aliada estratégica) frente a las naciones vecinas. En este sentido, en octubre de 2006 se presentaron ciertos niveles de tensión diplomática entre ambos países frente a las afirmaciones del presidente Evo Morales de que Estados Unidos estaba operando en la frontera chaqueña guaraní queriendo propiciar un enfrentamiento entre ambas naciones. Lo cierto, es que la actividad militar se incrementó en la región. Mientras que funcionarios estadounidenses visitaron las instalaciones del aeropuerto de Mariscal Estigarribia (construido durante el periodo de Stroessner por técnicos estadounidenses), en el Fortín boliviano ubicado en Ibibobo, se entrenan intensivamente tropas bolivianas -a 35 kilómetros de puesto militar paraguayo "Infante Rivarola"-.

Mas allá de la posición geoestratégica, los diferentes intereses, hipótesis de conflicto, y acciones militares que se realizaron en los últimos tiempos en esta zona, aquí nos interesa destacar el impacto que quedó grabado a sangre y fuego en el inconsciente colectivo ${ }^{80}$ de los paraguayos sobre el conflicto sucedido ya hace mas de 72 años, al punto tal que uno de los principales parques nacionales del norte del país lleva el nombre de "Defensores del Chaco", al igual que uno de sus grandes estadios de fútbol, el cual año a año consigue reactivar el sentimiento patriótico por medio de este deporte.

En síntesis, el episodio de la Guerra del Chaco vino a involucrar a Paraguay en un conflicto armado con el único país vecino con el que aun no había luchado, y terminó en una especie de profecía auto-cumplida de la amenaza externa desde el otro lado de las fronteras, pero además aglutinó en un solo conjunto el temor a la agresión, el orgullo nacional, el rol de los militares, y la validez de los gobiernos fuertes.

Desde entonces, el auto-retraimiento colectivo y la actitud aislacionista se consolidaron como basamento social, y marcó la mentalidad de las Fuerzas represivas del Estado y de sus elites hasta la actualidad. La hipótesis del enemigo exterior y de la amenaza vecinal ni siquiera perdió vigencia durante la guerra fría, a pesar de las redes de colaboración y cooperación establecidas con el resto de las dictaduras del Cono Sur en el marco del Plan Cóndor. Al igual que en otros países de la región, las Fuerzas Armadas guaraníes operaron como constructoras del Estado, defensoras del territorio nacional, pero al mismo tiempo garantes del orden social interno, características que en Paraguay encontraron niveles sumamente 
potenciados por todo lo descrito hasta aquí, y que dejaron sentadas las bases para una rápida fusión en materia de Seguridad y Defensa posible por las características diferenciadas de su proceso de transición a la democracia, y por las falta de un Estado de Derecho consolidado como tal. Las políticas públicas en materia de Seguridad se apoyan y sostienen a su vez sobre una subjetividad -influenciada por las secuelas provocadas por el terrorismo de Estado -la cual recibió el mensaje de que el silencio también era defensa y condición necesaria para sobrevivir, incidiendo a favor de salidas represivas. El mensaje de impunidad antes mencionado, y evidenciado en el periodo de transición y posteriores gobiernos paraguayos hasta la actualidad, impactó sobre la patología, que vendría dada por la denegación o prohibición de una traducción "propia" de la historia, y que se expresaría en un espectro de modalidades negativas entroncando desde el desconocimiento de un texto (que solo puede ser visto como ajeno, que "no me concierne" y sobre el que se apoya una conducta pasiva, apática, y políticamente delegativa), hasta la repetición inmodificada sin traducción ni actualización posibles (cuya peligrosidad reside en que el trauma reaparezca repetitivamente, aunque re-actualizado, habilitando desde nuevos autoritarismos hasta conductas paranoides y delatorias entre la población -incluso intra y entre clases oprimidas-, las cuales resultan un basamento funcional para la re-militarización de las relaciones sociales).

\section{Conclusiones}

Como se ha desarrollado a lo largo de la siguiente investigación, existen diversas variables que inciden sobre el diseño de las políticas públicas en materia de Seguridad y Defensa en Paraguay (entre 2001 y 2007), algunas de las cuales se encuentran su explicación en la propia historia del país, enmarcadas a su vez en un determinado contexto internacional que se caracterizó por un clima posterior al 11 de septiembre y por el rumbo que, a partir de entonces, trazó la administración de G. W. Bush. Luego de los atentados al Word Trade Center el gobierno estadounidense buscó profundizar algunas tendencias en el ámbito de Seguridad y Defensa hemisféricos que ya se venían delineando desde décadas anteriores. Iniciativas que encontraron un eco positivo en Paraguay (y en otros países como Colombia), cuyos sucesivos gobernantes se alinearon detrás de las propuestas de Washington emitiendo una serie de reglamentos como los planes, los decretos, y las leyes ya mencionados, fundamentadas en el supuesto objetivo de luchar contra las "nuevas amenazas" que asolan la post guerra fría. Las múltiples razones, las cuales no ha sido fácil identificar y ordenar en diferentes niveles, que permitieron a la administración republicana encontrar en las clases dominantes guaraníes una coincidencia de intereses, así como un terreno fértil para la instalación de su ideología en materia securitaria, las hemos resumido de la manera siguiente: 
a) Por una lado, se destaca la vivencia de las estructuras tradicionales de poder económico y político paraguayas sobre la situación de ingobernabilidad, las cuales se enfrentan a la movilización liderada por los movimientos campesinos tras el CDP entre 2001 y 2002. Los hechos sucedidos durante ese periodo terminarán conduciendo hacia una "reacción" apoyada en el fortalecimiento de los aparatos represivos y punitivos del Estado (e incluso para-estatales en el campo) con el fin de restaurar el orden y forzar una salida de la crisis que fue en detrimento de las clases subalternas.

b) Por otra parte, operó a favor de Estados Unidos un sentimiento histórico aislacionista-defensivo (que encuentra su explicación en los efectos que las guerras del pasado y también en las secuelas que el terrorismo de Estado han dejado en el inconsciente colectivo) de las elites locales, el cual posibilitó que éstas percibieran a la potencia del norte como un aliado menos peligroso frente a otros países como Brasil o Argentina, en tanto que las "hipótesis de conflicto" sobre la amenaza vecinal continúan vigentes.

Además resultaron funcionales (para el proyecto de dominación estadounidense) una tradición de colaboración militar entre ambos países que se remonta a los tiempos del Stroessner, así como la pervivencia de estructuras y prácticas autoritarias que no han sido desarticuladas ni penadas durante el proceso de "transición" democrática. En esta misma dirección se inscribe la inexistencia de una institucionalización y de una burocracia profesional, lo que se refleja en la ausencia de una justicia relativamente independiente del poder político (y con ciertos niveles de control ciudadano). Debido a lo cual se facilitaron (aún más) los rápidos cambios legales que habilitaron la fusión entre los ámbitos de Defensa y Seguridad (aprobando la actuación conjunta de fuerzas policiales y militares en tareas de Seguridad Interior).

En resumen, en un momento auto-proclamado por Estados Unidos como de "oportunidad histórica" para afianzar su hegemonía a nivel mundial, Paraguay apareció (debido a las razones históricas ya descriptas y a su coyuntura política) como un terreno propicio para la intervención del norte. Intervención militar que resultó geopolíticamente estratégica para los intereses estadounidenses, no solo permitiendo obstaculizar cualquier proyecto de integración sudamericano antihegemónico, sino también en tanto sirvió para asegurar el control sobre el cono sur (así como el aprovechamiento y depredación de los recursos naturales ${ }^{81}$ de la zona).

Por lo tanto, las políticas públicas de la nación guaraní terminaron viéndose atravesadas por los conceptos que la administración republicana promovía (con diversos resultados) a nivel continental, y que se caracterizaban por la falta de límites entre la esfera de lo civil y la de lo militar, la necesidad del control de 
flujos y de recursos trasnacionales legales o ilegales ya descriptos (en especial información, capital, y población), así como también por la importancia de la ocupación del territorio para generar infraestructura que permitiera una rápida llegada de las mercancías a los centros de poder en pos de sostener e incrementar los beneficios del denominado complejo militar-industrial (y de las empresas de capitales estadounidenses).

El argumento de la guerra antiterrorista entonces fue utilizado para fundamentar el disciplinamiento de organizaciones rebeldes, instituyéndose a través de una legalidad que opera a favor del reforzarmiento de mecanismos del control social. Elementos considerados necesarios por las clases dominantes locales e internacionales debido a la multiplicación de los movimientos sociales y de acciones de protesta en la región, los cuales cuestionan la injerencia militar, económica, y cultural, de la potencia hegemónica en América Latina. En consecuencia, la decisión que tomó el gobierno de G. W. Bush (sostenido en un pensamiento neoconservador que oficializa el «estado de excepción» y el de la guerra preventiva) de apoyar a los presidentes guaraníes González Macchi y Duarte Frutos a cambio de la promulgación de una legislación local que instale un precedente jurídico en materia de Seguridad y Defensa que Estados Unidos desea expandir hacia los demás países de la región, es considerada por la administración republicana como necesaria para su interés nacional.

Resta detallar de manera exhaustiva las consecuencias que estas reglas tuvieran sobre los sectores populares, investigar los espacios de tensión y resistencia que se constituyiran frente a esta doctrina securitaria (no solamente en Paraguay, sino también en la región y mismo dentro de la propia sociedad estadounidense), y el posible cambio de condiciones que generaran algunas propuestas de izquierda que podrían acceder al poder. Así como indagar las perspectivas futuras de este proceso histórico, las cuales se presentan complejas y deben enmarcarse en un contexto nacional y regional caracterizado, por la vigencia de gobiernos progresistas, definidos así en tanto no llegan al poder como expresión directa de las clases dominantes, pero que presenta tensiones endógenas y una pugna, no solo por los liderazgos en el sur del continente, sino también por la radicalidad de las reformas institucionales y económicas en materia democrática. En este marco, el nuevo gobierno guaraní deberá afrontar la herencia de un Estado debilitado, corrupto y con prácticas de tipo mafioso instaladas por décadas en los diferentes estamentos de sus capas burocráticas (y en especial al interior de las Fuerzas Armadas y fuerzas policiales); una crisis económica que ha conducido a la migración a gran parte de su pueblo (uno de los factores claves del repunte de la economía en 2007 fueron los mas de 600 millones de dólares de remesas enviados por los inmigrantes paraguayos que viven en el extranjero ${ }^{82}$ ); dificultades para sostener la gobernabilidad debido 
a lo heterogéneo de la alianza que sostiene a Fernando Lugo (la cual nuclea desde escisiones del Partido Colorado, partidos tradicionales como el Partido Radical Liberal Autentico, hasta un ala de movimientos sociales y partidos de izquierda radicalizados, todos plantados en torno a seis puntos programáticos sumamente generales que apenas se han podido consensuar con suma dificultad en el periodo previo a la campaña electoral); un proceso histórico de concentración de la tierra y de auge del modelo sojero que ha conducido al incremento de las desigualdades en la distribución de la riqueza y que es permanente fuente de conflicto; y el incremento de los niveles de pobreza extrema que, egún la Encuesta Permanente de Hogares de $2007^{83}$, trepó del 15 al 19, 3\% en los últimos dos años afectando a un total de 1.172.312 personas (mientras que el 36, $6 \%$ de la población, o sea, el 35, 6\%, es pobre). Deberá enfrentar formas de administración del conflicto social en una sociedad politizada, donde operan movimientos sociales sumamente activos en sus bases, muchos de los cuales apoyaron la candidatura de Lugo, que se encuentran decididos a imponer sus postergadas demandas al Estado.

Una mirada hacia el pasado y las herencias y condicionamientos que afronta la APC en materia de aparato represivo del Estado, intenta ser un aporte para las políticas públicas securitarias a construirse en el futuro.

\section{NOTAS}

I O’ DONELL, G., "Apuntes para una teoría del Estado". In: Teoría de la burocracia estatal, Buenos Aires: Paidos, 1984, p. 34-56.

Ver también OZLAK, O. y O’ DONELL, G. Estado y políticas estatales en América Latina: hacia una estrategia de investigación. Caracas: Monte Ávila, 2003.

2 Para Gramsci, las clases subalternas -subproletariado, proletariado urbano, rural y también la pequeña burguesía - no están por lo general unificadas. Su tendencia a la unificación es despedazada continuamente por la iniciativa de los grupos dominantes, de los cuales ellas "sufren" siempre la iniciativa, aún cuando se rebelen y se insurreccionen. El problema central para la teoría marxista, reside entonces en comprender como puede el proletariado rural y urbano, o en general una clase dominada, subalterna, volverse clase dirigente y ejercitar el poder político, o sea convertirse en una clase hegemónica. In: GRAMSCI, A. Antología. Buenos Aires: Siglo XXI Editores, 2006, p. 49I.

3 Definidos en términos de una acción colectiva concertada por medio de la cual "una categoría social, siempre particular, pone en cuestión una forma de dominación social, a la vez particular y general, e invoca contra ella valores, orientaciones generales de la sociedad que comparte con su adversario para privarlo de tal modo de legitimidad". In: TOURAINE, A. ¿Podremos vivir juntos?. Buenos Aires: Fondo de Cultura Económica, 1997, p. 100.

4 La Central Nacional de Trabajadores, CNT; la Confederación Paraguaya de Trabajadores, CPT; la Central Unitaria de Trabajadores, CUT; la Central Sindical de Trabajadores Paraguayos, CESITEP; la Central General de Trabajadores, CGT; y la Central Unitaria de Trabajadores Auténtica, CUTA.

5 FOGEL, R., "La estructura y la coyuntura en las luchas del movimento campesino paraguayo" y "Movimientos campesinos y su orientación democrática en el Paraguay". In: La construcción de la democracia en el campo latinoamericano. Buenos Aires: CLACSO, 2006, p. 95- 105.

6 RIQUELME, Q., "Los conflictos sociales en el contexto de la democracia paraguaya". In: Movimientos 

al nuevo escenario político

sociales y conflicto en América Latina. Buenos Aires: CLACSO, 2004. p. 55-60. Y RIQUELME, Q. Los sin tierra en Paraguay. Buenos Aires: CLACSO, 2003.

7 En este sentido, autores como Robert Cox afirman que la hegemonía sostiene un tipo de orden donde el modo de producción dominante penetra en todos los países y se relaciona con otros modos de producción subordinados, formando una compleja red de relaciones sociales internacionales que vincula a las clases sociales de las distintas naciones, resultando más consistente en el centro, pero también generando mayores contradicciones en la periferia.

8 La moneda oficial-el guaraní- tuvo una devaluación de más del 30 por ciento frente al dólar, afectando notoriamente la canasta de los trabajadores y trabajadoras tanto de la ciudad como del campo, debido a su dependencia de la producción importada lo que torna a la economía paraguaya sumamente vulnerable a las oscilaciones de la moneda estadounidense. Ver PILZ, D., RIQUELME, Q., VILLALBA, V., "Los movimientos sociales en el contexto actual del Paraguay" In: OSAL. Buenos Aires: CLACSO, 2006, p. 26. 9 Idem.

10 Idem, p. 27.

I I Siglas de la Coordinadora Agrícola del Paraguay, gremio que aglutina a medianos y grandes productores agropecuarios de los departamentos de Alto Paraná, Itapúa, y Canendiyú, aunque la CAP no se manifestaba expresamente contra la privatización, si reclama por la reforma del proyecto de la Banca Pública por considerarlo lesivo para sus intereses.

12 Ver: www.mnd.gov.py, www.camdip.gov.py, y www.senado.gov.py

I3 RIQUELME, Q. Los sin tierra en Paraguay. Buenos Aires: CLACSO, 2003, p. 55.

14 Entrevista realizada por Quintín Riquelme a Eladio Flecha -presidente de la FNC- en el 2000. Ibid.

I 5 Ver RIQUELME, Q. Los sin tierra..., op. cit., p. 56.

16 Ver PILZ, D., RIQUELME, Q, VILLALBA, V. “Los movimientos...”, op. cit., p. 27-29.

17 Aspecto que Gramsci considera necesario y previo a una crisis de hegemonía y coligado con una situación revolucionaria.

I8 En alusión al quinto presidente de los Estados Unidos quien gobernó entre 1817 y 1825.

19 LABATUT, B. "Les défis multiformes de la sécurité au Paraguay : démocratie/développement/sécurité, combinaison miracle pour le XXle siècle ?». In : Revue des Sciences Politiques n 56, p. 17. Paris, 2006.

20 Dentro del marco de la denominada Doctrina de Seguridad Nacional hasta 1984, fueron enviados a la famosa Escuela de las Américas estadounidense para ser entrenados unos II 50 efectivos militares paraguayos.

2I Ver declaraciones del Canciller José Antonio Monero Rufinello en Ultima Hora, 18/9/200 I.

22 Ver VALIENTE, H. "Detenciones ilegales y arbitrarias" In: Derechos Humanos en Paraguay 2001. Asunción: Litocolor, 2001 , p. 85.

23 CASTILLO, O. "Derecho a la Paz y al Desarme. Fuerzas Armadas se consideran en guerra". In: Derechos Humanos en Paraguay 2002. Asunción: Litocolor, 2002, p. 445.

24 Ver www.camdip.gov.py

25 Según BURGOS SILVA, G., investigador del Instituto Internacional de Gobernabilidad de Barcelona, la construcción de un Estado sujeto al Derecho esta ligada a principios esenciales como el reconocimiento y garantía de los derechos humanos, la enunciación y aplicación de la seguridad jurídica, la división y control entre los poderes públicos, y el fortalecimiento del sistema judicial, principios o condiciones que no reúne el Estado paraguayo. Este autor destacara la casi inexistencia de una legalidad administrativa, la excesiva concentración de funciones de la Corte Suprema de Justicia, así como los numerosos problemas que presenta la falta de independencia del poder judicial del poder político y los grandes poderes económicos, legales e ilegales. Insistiendo en que, pese a la reconfiguración institucional realizada a partir de 1992, el Estado paraguayo se encuentra mas bien enmarcado en una legalidad pero no sujeto a ella.

26 QUINONEZ, J. C., GORTARI, M. C., SCKELL, L. M., "Ministerio Publico y Seguridad Ciudadana en el Paraguay". In: Nueva Sociedad n 191, p. I 18. Asunción: mayo-junio 2004.

27 En este sentido se argumenta que el Ministerio Público de Paraguay cuenta con una estructura organizacional y una presencia territorial-organizada en áreas, regiones y zonas- que le posibilitarían realizar un mejor trabajo que el Ministerio del Interior. Ibid., p. 122. 
28 Para una investigación sobre este tipo de conductas se recomienda IGLESIAS, J. G., WINER, S. V., GONZALES TIZON, H. P., GONZALEZ, A. R. Construcción de la memoria colectiva. Buenos Aires: Eudeba, 2003.

29 Ver ZALASAR, S. "Actores imaginarios o imaginarios sin actores". In: Revista Espiral n I 7, p. 22, México DF, 2000.

30 Esta doctrina de gran éxito a fines de los años noventa tiene como fin penalizar a los integrantes de la sociedad expulsados de las márgenes del mercado laboral y abandonados por un Estado que otrora fuera social, actuando con severidad frente a los "desórdenes", y liberar a ese mismo estado de sus responsabilidades en la génesis social y económica de la inseguridad para apelar a la responsabilidad individual de los habitantes de las zonas de pocos recursos, a quienes correspondería en lo sucesivo ejercer por sí mismos un control social estrecho para "limpiar las calles". Una de las grandes consecuencias de este pensamiento aplicado ya en varias ciudades del mundo, pero principalmente en Nueva York, ha consistido en haber ahondado un abismo de desconfianza (y en el caso de los más jóvenes de desafío) entre la comunidad afroamericana o de color y las fuerzas del orden, en fomentar una mirada racista que penaliza la miseria. Sobre este tema se recomienda ver WACQUANT, L. Las cárceles de la miseria. Buenos Aires: Manantial, 2000.

3I Quien plantea desde sus publicaciones en la revista Atlantic Monthly: todo un recetario para mantener una supremacía de "bajo perfil" (stealth supremacy), por medio de una intensificación del paramilitarismo, las operaciones clandestinas, el asesinato y la violencia contrainsurgente. Por ejemplo, auspicia el uso de fuerzas locales bajo la dirección de asesores militares de Estados Unidos en Arauca, Colombia, importante por sus recursos de hidrocarburos. SAXE-FERNANDEZ, J, "La ideologia conservadora y el gobierno de Bush" In:, Economia y Sociedad n²4, p. 6. Costa Rica, 2004.

32 Entrevistados en el marco de la Misión de Observación Internacional realizada por la Campaña por la Desmilitarización de las Américas "CADA- entre el 15 y el 20 de julio de 2006 en Paraguay.

33 BURGOS SILVA, G. "Estado de Derecho en Paraguay... ", op. cit., p. I -6. Sobre episodios de corrupción, por ejemplo, al interior de las Fuerzas Armadas, se recomiendan leer las investigaciones de BENEGAS VIDALLET, J. tituladas Unos 13.000 millones al año se estarían estafando de la caja militar, El fraude en jubilación y pensiones desangra la caja militar, La decadencia rapínera de un tipo de Fuerzas Armadas , Siguen farreando el presupuesto militar, publicadas por el diario ABC, www.abc.com.py , [Consultado el 5/II/2007].

34 Ver CADA, Informe Misión de Observación Internacional-Paraguay. Buenos Aires: 2006, p. 15.

35 Ver www.presidencia.gov.py

36 Ver CADA, Informe Misión de Observación Internacional-Paraguay. Buenos Aires: 2006, p. | 4- I5.

37 Se calcula que entre 2002 y 2006 se han realizado 59 cursos, ejercicios militares, y actividades diseñadas, financiadas y lideradas por funcionarios militares que responden Pentágono. Al mismo tiempo que un importante incremento de visitas de altos funcionarios estadounidenses.

Ver CADA, Informe Misión de Observación Internacional-Paraguay ,2006, p. 9.

38 Son las siglas de Medical Readiness Training Exercises, que consisten en operativos de prestación de servicios médicos de variado tipo a la población civil de una región.

39 MANERO, E. "Succincte introduction aux transformations stratégiques de l'après-guerre froide. L'Amérique latine dans le désordre global" In : L'Ordinaire Latino Americain, n 195, p. 16. Toulouse, Janvier-Mars 2004.

40 lbid., p. 28 y 29.

4 I Instancia judicial supranacional que no es reconocida por el Estado estadounidense.

42 Ver www.presidencia.gov.py

43 Ver en www.senado.gov.py, Resolución 503 de la Cámara de Senadores. Por la cual se autoriza el ingreso al país de tropas de las Fuerzas de los Estados Unidos de América, solicitada por el Poder Ejecutivo, según mensaje N 282 del 7 de junio de 2005.

44 Ver diarios ABC, Ultima Hora, y Diario Noticias de marzo a mayo de 2004.

45 Ver www.senado.gov.py

46 CECEÑA, A. E. "La guerra como razón del mundo" In: Moloch Siglo XXI. A propósito del imperialismo y las cumbres. Buenos Aires: Ediciones del CCC, 2005, p. 57. 

al nuevo escenario político

47 FOUCAULT, M. Genealogía del racismo, citado en Ibid., p. 55.

48 La CEPAL estimaba en 1999 la existencia de 89 millones de personas en Latinoamérica en situación de indigencia.

49 A un mundo donde prevalece la desconfianza y la competencia, donde la vida es corta y cruel. Ver. HOBBES, T. El Leviatán. Madrid: Editora Nacional, 1983.

50 La calificación de "asimétrica" remite al enfoque interdependentista según el cual diferentes capacidades no suponen relaciones de dependencia entre diferentes poderes. Al ser "asimétricas", las amenazas provienen de agentes no estatales, intra o trasnacionales, y su principal característica es la imprevisibilidad respecto del momento y la forma de ataque. Lo novedoso estas acciones asimétricas radica en el empleo de la tecnología y en su impacto mediático, y las mismas resultan muy diferentes a la «amenaza tradicional» que provenía de un Estado y era de carácter territorial.

La Estrategia de Seguridad Nacional publicada por la Casa Blanca el 17 de septiembre de 2002 se centra en este concepto para el rediseño de sus propias Fuerzas. Para este tema se recomiendo leer BEDAR, S. "L'asymétrie comme paradigme central de la stratégie américaine" In: Le Débat Stratégique n56, 200 I, www. cirpes.net, [Consultado el 26//2/2006].

5I GAVEGLIO, S., TANZI, L. "El contenido de la Agenda de las Américas en Defensa y Seguridad en pos guerra fría. Un análisis crítico" In: L’Ordinaire Latino Américain n 195, p. 72. Toulouse, 2004.

52 CIA, "Globaltrends 20I5", <www.cia.gov>, [Consultado el 23/I0/2003].

53 CECEÑA, A. E., MOTTO, C. Paraguay: eje de la dominación del Cono Sur. Buenos Aires: OGLE Ediciones, 2005, p. II

54 Desde 1998 Estados Unidos conformo con los gobiernos de la región la Comisión Tripartita de la zona de la Triple Frontera (conocido como el «pacto 3 mas | ») -presentado como un mecanismo de Seguridad para la cooperación de los cuatro países en la prevención y lucha contra el terrorismo-. En diciembre de 2003, una delegación interinstitucional estadounidense asistió a una reunión especial en Paraguay con el fin de proponer el establecimiento de un centro regional conjunto de inteligencia. Esta proposición debe ser interpretada en el marco de la estrategia estadounidense de obtener el control de flujos y stocks legales e ilegales, pero también en el que se interpreta la información como elemento de guerra.

55 Este sistema acuífero -en gran parte subterráneo- abarca un área aproximada de I. 195.700 km2 y sus reservas de agua (su capacidad de almacenamiento) se estiman en $40.000 \mathrm{~km} 3$, con una recarga de 160 km3. Por lo tanto se estima que estas reservas podrían satisfacer las demandas de agua de 360.000 .000 de habitantes -300 litros diarios por persona- a lo largo de 100 años, agotando solo un $10 \%$ de su capacidad total. Esta inmensa riqueza natural se encuentra justo debajo de los países del MERCOSUR (70\% bajo suelo brasileño, $19 \%$ en Argentina, 6\% en Paraguay y 5\% en Uruguay) y acaba de ser descubierta recientemente. A pesar de que la embajada estadounidense en Paraguay a negado públicamente su interés en el SAG, la agencia gubernamental de Estados Unidos-USAID- expresa de manera clara en su pagina web el valor y la importancia que representa esta reserva para la potencia del norte -que posee la mayoría de sus acuíferos y ríos contaminados y que, se estima, dentro de 10 años no tendrá la capacidad de abastecer a sus ciudadanos con agua potable-.

Para conocer mas sobre los estudios isotópicos, los proyectos de estudios sobre este acuífero que propician diferentes agencias estatales, instituciones internacionales y universidades regionales, ver www. sg-guarani.org

56 Llamado Network centric warfare. Ver CECEÑA, A. E., MOTTO, C. "Paraguay: eje de la dominación", op. cit., p. 21 . Se recomienda también navegar el sitio www.arpa.mil

57 Ibid.

58 Donde se ha denunciado la existencia de antenas satelitales en medio del Chaco paraguayo supuestamente con el objetivo de realizar espionaje sobre la Bolivia presidida por Evo Morales, información que hasta el momento la autora no ha podido confirmar y que considera una tarea pendiente en un futuro trabajo de terreno.

59 Localidad en la que se están realizando obras de infraestructura para ampliar las instalaciones de un centro estadounidense de la DEA.

60 Ver www.senado.gov.py 
6 I Sigla correspondiente al proyecto "Alternativa Latinoamericana Bolivariana para las Américas" promovida por los presidentes Hugo Chávez Frías y Fidel Castro Ruiz.

62 OEA, Declaración sobre Seguridad en las Américas, Sección II, Párrafo 4, inciso m.

63 Sistema que toma forma mediante normas y reglas que tienden a limitar la soberanía a favor de procesos de decisión globales cuyos objetivos serian garantizar la seguridad de la economía global. MANERO, E. "Strategic Representations, Territory and Border Areas: Latin America and Global Disorder" In: Geopolitics $\mathrm{n}^{\circ}$ 12, p. 20, 2007.

64 lbid., p. 19 y 23.

65 Para mas información sobre este proyecto se recomienda navegar el sitio web www.ïrsa.org>

66 A la manera de los demás países del Cono Sur (incluyendo Brasil), los que en algún momento del siglo XIX vivieron las constitución de un acuerdo básico al interior de la oligarquía (a pesar de ser esta heterogénea) cuyo reverso fue la exclusión de los sectores populares en la toma de decisiones. Esta medida en detrimento de las clases subalternas (y que se adquirió de manera tardía previo paso por periodos plagados de conflictos: guerras entre fracciones, militarismo, caudillismo, conflictos entre capital y provincia, luchas entre republicanos y monárquicos, etc.), sin embargo fue la que permitió finalmente un mínimo de estabilidad política e institucional que alentó una acumulación temprana en torno a ciclos exportadores breves, pero exitosos. Paraguay no contó con ciclos exportadores exitosos como los de otros países del cono sur, que se expresaran en un valor elevado y constante de sus exportaciones (a pesar de que su actividad interna se había dinamizado por la significativa inversión publica). Luego de 1870, el desastre producido por la guerra (expresado por ejemplo en su terrible caída demográfica) y sus efectos posteriores sobre la destrucción de capital fijo e instalaciones productivas, sumado a una era subsiguiente de profunda inestabilidad política -que para colmo tropezó con los efectos de otras dos guerras: la del Chaco en 1932 y la Guerra Civil de 1947- no consiguieron revertir en Paraguay su propensión al estancamiento y a un crecimiento muy pequeño.

Se podría decir que existieron solamente dos periodos de crecimiento económico y que se destacan -a pesar de sus muy diferentes características- como momentos excepcionales de la historia económica guaraní: el primero bajos los gobiernos de Schaerer y Franco (1912-1919) y con Ayala (1923-1928); y el segundo bajo la dictadura de Stroessner pero solo entre 1970 y 198I (que coincide con la elevada inversión externa y publica que rodearon al proyecto de construcción de Itaipú).

Luego de una nueva crisis entre 1982 y 1983 (producto del impacto de la crisis de la deuda que asolo a la mayoría del continente), retorna un incremento moderado entre los años 1984 y 1985 y un repunte entre 1987-1989.

La primera mitad de la década del noventa también continuaría esta tendencia hasta el estancamiento de 1996.

En todo caso, lo que interesa destacar, es que -a diferencia de otros vecinos- desde 1870 hasta la actualidad Paraguay no pudo disfrutar ni de los altos rendimientos que otras economías de la región lograron durante el ciclo primario-exportador (comprendido entre el ultimo cuarto del siglo XIX y la crisis de 1929), ni tampoco pudo participar de los escasos -pero significativos- logros de obtenidos por otras naciones durante el denominado ciclo sustitutivo de las importaciones y de industrialización inducida por el Estado entre 1929-1970/80.

Varios son los factores que truncaron este proceso de formación y reproducción ampliada de los stocks de capital -que para consolidarse precisa de elevadas cifras de crecimiento del producto y una cierta constancia en el tiempo-. El mas evidente es la ausencia de una clase o agente capitalista que lo promueva y que se conforme como sector empresario o burguesía.

67 En este sentido, el Partido Colorado no ha conseguido constituirse como acuerdo valido que represente al menos a la mayoría de los distintos componentes del grupo dominante; aunque si ha respondido como factor aglutinador en coyunturas de excesiva conflictividad social (por ejemplo entre el 200 I y el 2002) y frente a la amenaza sistémica que en este periodo representa la acumulación de fuerzas y el incremento de los niveles de organización de las clases subalternas.

68 Frente a una situación de crisis «orgánica», Gramsci dice que el bloque ideológico que da cohesión y hegemonía a la sociedad tiende a disgregarse, por lo que la clase dominante deja de cumplir su dirección 


\section{Las políticas de Seguridad y Defensa en Paraguay: perspectivas y desafíos frente al nuevo escenario político}

económica y cultural. Este autor menciona como un ejemplo de este tipo de crisis un proceso en el que vastas masas pasan de golpe de la pasividad política a una cierta actividad y plantean reivindicaciones que en su caótico conjunto constituyen una situación revolucionaria. Esto significa la politización de las clases subalternas y su «escisión» de la clase dominante (lo que no necesariamente desemboca en una salida revolucionaria, como veremos luego). La «crisis orgánica» o «crisis de hegemonía» afecta principalmente a la sociedad civil que pone en cuestionamiento a la clase dominante y su conducción política forzándola hacia diferentes «salidas»: la más utilizada consiste en la reestructuración de esa misma sociedad civil, donde la clase dirigente tradicional tiene un numeroso personal adiestrado y cambia hombres y programas reasumiendo el control que se le estaba escapando con una celeridad mayor de cuanto ocurre en las clases subalternas. Estos cambios o mutaciones estarían mediadas por intelectuales «orgánicos» a las clases dominantes ubicados dentro de las organizaciones de la sociedad civil, pero también por una reforma del aparato estatal que es utilizado para aplastar la dirección de las clases subalternas y separarlas de sus intelectuales por la fuerza o por la atracción política. Pensamos que éste ultimo análisis puede colaborar en la explicación de la estrategia que se utilizó para disciplinar a los sectores populares movilizados en Paraguay en 200I.

69 Ver MELIA, B. "Y al final iqué es un campesino paraguayo?". In Acción n²02, <www.uninet.com.py $>$, [Consultado el 28/I0/200I].

70 lbid.

7I Ver www.redrural.org.py

72 ALMEYRA, G., "Paraguay: todo dependerá de las movilizaciones sociales". In: La Jornada de México, p. 4-6, México DF, 27/4/2008.

73 También funcionales a la consolidación de redes clientelares y relaciones de patronazgo promovidas en las ultimas décadas por el partido colorado y otros grupos de poder.

74 Que a su vez se complementa con la percepción de que las miradas externas no comprenden, subvaloran, o critican injustamente los modelos de organización nacional.

75 Aunque debe tenerse en cuenta que éste es un término polisémico que ha sido utilizado de muy diversas maneras y al que se le han asignado interpretaciones antagónicas, en especial en los capitalismos periféricos.

76Existe un debate historiográfico a propósito de las causas de esta guerra . Ver ROSA, J. M. La Guerra del Paraguay y las montoneras argentinas. Buenos Aires: Hyspamérica, 1986. SCENNA, M. A. ArgentinaBrasil: Cuatro siglos de rivalidad. Buenos Aires: La Bastilla, 1975. HALPERIN DONGHI, T. Una nación para el desierto argentino. Buenos Aires: Centro Editor de América Latina, 1982. BOX, P. H. Los orígenes de la Guerra de la Triple Alianza. Buenos Aires-Asunción: Nizza, 1958. BAEZ, C. Resumen de la historia del Paraguay desde la época de la conquista hasta el año 1880. Asunción: H. Kraus, 19I0. WARREN,H. G Paraguay and the Triple Alliance. The Postwar Decade, 1869-1878. Texas: University of Texas Press, 1978.

77 Interpretación que no comparten miradas y organizaciones de izquierda y del movimiento social que rescatan la figura y ciertos aspectos de la gestión del presidente Solano López.

78 Donde hacia 1920 se había descubierto petróleo y ahora se estima nuevamente que en sus subsuelos se encuentran recursos energéticos y acuíferos, sospechas que aun no han sido corroboradas de manera contundente.

79 Siglas de Agencia de los Estados Unidos para el Desarrollo Internacional.

80 Entendido según la definición de Carl Gustav Jung, para quien el inconsciente es constitutivo de todo aquello que nos es consciente, autor que se sitúa en la línea de la escuela francesa de Paul Janer. KAES, R. "Rupturas Catastróficas y trabajo de la memoria. Notas para una investigación" In: Violencia de Estado y Psicoanálisis. Buenos Aires: CEAL, APDH, 1991.

81 En especial en materia acuífera, energética y de biodiversidad.

82 RIQUELME, Q., Informe de coyuntura enero-febrero de 2008. Buenos Aires: CLACSO, 2008.

83 Publicada en el sitio de la Dirección General de Estadísticas, Encuestas y Censos. Ver : www.dgeec. giv.py 